Résumés des conférences et travaux

\title{
Les inscriptions royales assyriennes
}

\section{Lionel Marti}

\section{(2) OpenEdition}

Journals

Édition électronique

URL : https://journals.openedition.org/ashp/613

DOI : 10.4000/ashp.613

ISSN : 1969-6310

Éditeur

Publications de l'École Pratique des Hautes Études

\section{Édition imprimée}

Date de publication : 1 octobre 2009

Pagination : 9-10

ISSN : 0766-0677

\section{Référence électronique}

Lionel Marti, «Les inscriptions royales assyriennes », Annuaire de l'École pratique des hautes études (EPHE), Section des sciences historiques et philologiques [En ligne], 140 | 2009, mis en ligne le 02 octobre 2009, consulté le 06 juillet 2021. URL : http://journals.openedition.org/ashp/613; DOI : https://doi.org/ 10.4000/ashp.613 


\title{
LES INSCRIPTIONS ROYALES ASS Y RIEN NES
}

\author{
Chargé de conférences : M. Lionel MARTI
}

Programme de l'année 2007-2008: Introduction à la lecture des textes historiques assyriens.

La conférence de cette année a débuté par la présentation du sujet étudié ainsi que de ses objectifs. Son but était de présenter aux auditeurs les textes laissés par les monarques assyriens, en les confrontant dans la mesure du possible à la réalité du document, suivant la remarque très pertinente de G. Perrot et C. Chipiez, Histoire de l'art dans l'Antiquité, tome premier : l'Égypte, 1882, p. XIII, « Tout ne s'apprend pas dans les livres. Voulez-vous parler d'art avec quelque compétence, commencez par étudier de près les œuvres de la plastique, entretenez avec elles un commerce intime et familier ... ». Ainsi, plutôt que d'étudier ces textes à partir de transcriptions et de traductions, les auditeurs ont-ils été mis face aux divers modes de publication de ces différents textes, qui permettent l'accès direct à l'écriture cunéiforme : à savoir, des copies (de différentes époques), des photos, ou des originaux. Par ailleurs, lorsque cela était possible, ces différentes sources étaient comparées et critiquées, la confrontation entre la copie et la photo d'un même document pouvant montrer de grandes disparités.

Puis, nous avons présenté la définition d'une « inscription royale assyrienne » et les problématiques actuelles associées à ce genre littéraire.

Dans la première partie de l'année, on a tiré les conclusions du cours de l'année précédente, qui donnait un aperçu général des inscriptions royales assyriennes, grâce à une sélection d'exemples, pris chronologiquement à partir d'Assur-uballiṭ I ${ }^{\mathrm{er}}$ (1353-1318), que l'on considère comme le fondateur de l'empire assyrien, jusqu'à Aššurnașirpal II (883-859), souverain renommé pour sa cruauté. Le cours a débuté par l'étude de deux inscriptions d'Aššurnașirpal II car il s'agit de textes classiques lesquels, malgré la masse qu'ils représentent, obéissent toujours à un modèle défini.

La première, rééditée récemment par A. K. Grayson, Assyrian Rulers of the Early First Millenium BC I (1114-859 BC), Toronto - Buffalo - Londres, 1991 (RIMA, 2), p. 299-300, commémore la construction de la nouvelle capitale assyrienne, Kalhu (Nimrud). Ce court texte (26 lignes), qui comporte une version abrégée de la titulature du souverain, une présentation résumée de l'étendue de l'Empire assyrien et un récit de construction des plus brefs, nous a permis de faire le point sur la structure d'une inscription de fondation.

La seconde, mise en parallèle avec la première, est une portion de ce que l'on appelle les «Annales » d'Aššurnașirpal II, gravées sur les bas-reliefs du temple du dieu Ninurta à Kalhu (voir A. K. Grayson, op. cit., p. 191-223). Ce morceau choisi (1. i 106-ii 2) décrit une partie de la deuxième campagne du souverain, ce qui nous permit d'aborder le thème de la punition des rebelles. Les deux cas présentés illustrent 
une répression décrite de façon particulièrement détaillée. Une partie de la population est mutilée, des monuments composés de différentes parties du corps des adversaires sont érigés aux alentours de la ville détruite et le chef de la rébellion est emmené en Assyrie pour y être écorché. Cela a été l'occasion de discuter la rhétorique des inscriptions royales et de poser la question de la véracité de leurs descriptions.

La seconde partie de l'année a été consacrée à l'étude de l'accession au trône du souverain Assarhaddon. Il s'agit d'un des textes classiques de l'Assyriologie décrivant l'aventure rocambolesque d'un jeune fils du roi Sennacherib, que rien ne destinait au trône d'Assyrie et qui finit par devenir roi, certainement suite à une conjonction de facteurs tels que la mort du fils héritier de Sennacherib, Aššur-nâdin-šumi, très certainement assassiné par les Élamites alors qu'il était vice-roi de Babylone, l'influence de sa mère, Naqi'a, et son sens politique certain. Le plus fameux récit qu'Assarhaddon donne de son accession au trône provient d'un prisme retrouvé à Ninive (Nin A : R. Borger, Die Inschriften Asarhaddons Königs von Assyrien, Graz, 1956 [AfO Beih 9], p. 36-37). L'épisode, de quelque 93 lignes, est un des documents fondamentaux qui illustrent cette période.

Après avoir présenté sa titulature, Assarhaddon rappelle son statut de fils cadet « J'étais le jeune frère de mes grands frères ». Suit un passage décrivant le processus de sa désignation comme prince héritier, proclamé par son père car choisi par les dieux. Ce dernier fit prêter un serment de fidélité à l'ensemble des gens du pays d'Aššur, puis fit entrer son fils dans la « maison de succession ». C'est alors que ses frères, dépités, complotèrent, en tentant notamment de faire changer d'avis leur père. Assarhaddon s'enfuit, sous la protection bienveillante des dieux, pour échapper à la vindicte de ses frères. Après plusieurs péripéties, il revint à la tête de ses troupes, marchant sur la capitale, et remporta la victoire.

Après avoir traduit le texte, le commentaire porta tout d'abord sur la notion de propagande royale et sur la valeur historique d'une telle documentation. Pour ce faire, il a été possible de comparer certains éléments du récit avec d'autres types de documents contemporains, et de déterminer ainsi quels aspects du récit ont été choisis ou oubliés, comme par exemple la mention de l'assassinat du père, lequel est sciemment omis, alors qu'il nous est connu par ailleurs, ce qui fit soupçonner par certains historiens Assarhaddon de parricide, jusqu'à ce que S. Parpola nous livre le nom de l'assassin (S. Parpola, CRRAI, 26 [1980], p. 171-182). Une attention plus particulière a été portée à la description du rôle des sciences divinatoires tel que le récit nous le présente, lequel est en parfaite adéquation avec ce que les ouvrages savants de l'époque nous enseignent, notamment les hémérologies en tant que sciences des jours fastes.

Le dernier cours de l'année porte habituellement sur un document original, que les auditeurs doivent traduire, suite à l'expérience acquise en cours d'année.

Cette année, il s'agissait d'un clou de fondation d'Aššur-bêl-nišê-šu, dont un exemplaire fragmentaire est conservé à la Section. Il s'agissait, en associant l'inscription fragmentaire de l'EPHE avec les 13 autres fragments connus, de reconstituer le texte complet et de familiariser ainsi les auditeurs avec les procédés d'élaboration d'un texte de référence à partir de fragments multiples et de versions parallèles. 